\title{
Work Preferences, Life Values, and Personal Views of Top Math/Science Graduate Students and the Profoundly Gifted: Developmental Changes and Gender Differences During Emerging Adulthood and Parenthood
}

\author{
Kimberley Ferriman, David Lubinski, and Camilla P. Benbow \\ Vanderbilt University
}

\begin{abstract}
Work preferences, life values, and personal views of top math/science graduate students (275 men, 255 women) were assessed at ages 25 and 35 years. In Study 1, analyses of work preferences revealed developmental changes and gender differences in priorities: Some gender differences increased over time and increased more among parents than among childless participants, seemingly because the mothers' priorities changed. In Study 2, gender differences in the graduate students' life values and personal views at age 35 were compared with those of profoundly gifted participants (top 1 in 10,000, identified by age 13 and tracked for 20 years: 265 men, 84 women). Again, gender differences were larger among parents. Across both cohorts, men appeared to assume a more agentic, career-focused perspective than women did, placing more importance on creating high-impact products, receiving compensation, taking risks, and gaining recognition as the best in their fields. Women appeared to favor a more communal, holistic perspective, emphasizing community, family, friendships, and less time devoted to career. Gender differences in life priorities, which intensify during parenthood, anticipated differential male-female representation in high-level and timeintensive careers, even among talented men and women with similar profiles of abilities, vocational interests, and educational experiences.
\end{abstract}

Keywords: math/science talent, circumscription and compromise, eminence, evolutionary psychology, vocational psychology

Supplemental materials: http://dx.doi.org/10.1037/a0016030.supp

Although gender differences are apparent in several personality attributes relevant to career development (Browne, 2002; Hedges \& Nowell, 1995; Lippa, 1998, 2006; Rhoads, 2004; Strand, Deary, \& Smith, 2006), most of the recent scholarly and public debate on women's underrepresentation in high-intensity science, technology, engineering, and math (STEM) careers has focused on the contribution made by gender differences in the

Kimberley Ferriman, David Lubinski, and Camilla P. Benbow, Department of Psychology and Human Development, Vanderbilt University.

Support for this article was provided by a research and training grant from the Templeton Foundation and National Institute of Child Health and Development Grant P30 HD 15051 to the Vanderbilt Kennedy Center for Research on Human Development. Earlier versions of this article benefited from comments from Rosalind Arden, Rene V. Dawis, David C. Geary, Linda S. Gottfredson, Harrison G. Gough, Wendy Johnson, Gregory Park, Georgine Pion, Stephen E. Rhoads, Jeffry A. Simpson, Stijn Smeets, James H. Steiger, Auke Tellegen, Andrew J. Tomarken, Niels G. Waller, Jonathan Wai, and Rose Mary Webb.

Correspondence concerning this article should be addressed to Kimberley Ferriman, David Lubinski, or Camilla P. Benbow, Department of Psychology and Human Development, 0552 GPC, 230 Appleton Place, Vanderbilt University, Nashville, TN 37203-5721. E-mail: kim.ferriman@vanderbilt.edu, david.lubinski@vanderbilt.edu, or camilla.benbow@vanderbilt.edu abilities requisite for outstanding achievement in STEM (Ceci \& Williams, 2007; Halpern et al., 2007). Perhaps this is because that topic (gender differences in abilities) is so controversial and emotionally charged. However, gender differences in lifestyle preferences and orientation toward life may be more important to women's underrepresentation in high-intensity STEM careers than one might conclude from the relatively small amount of attention devoted to them in the literature. Lifestyle preferences and orientation toward life refer to priorities and sources of life satisfaction including and beyond career fulfillment, such as work-family balance, community involvement, and relationships with others. The research described here investigates gender differences in lifestyle preferences among men and women who have the ability, passion, and training to excel in high-intensity STEM careers. Our approach not only in essence holds ability constant but also narrows the population down to the one most relevant for study: those who are supremely qualified to work in high-intensity STEM careers.

During the process of choosing a career, people gauge the compatibility of their lifestyle preferences with the lifestyle requirements of potential careers. However, lifestyle requirements are only one of many aspects that people consider in this process. According to Gottfredson's $(1981,2005)$ theory of circumscription and compromise, people also consider the career's gender type (whether it is typically held by men or women), its prestige level, 
its vocational interest requirements, and its ability requirements. First, over the course of childhood and adolescence, individuals eliminate from consideration occupations that are incongruent with their ideal career's gender type, prestige, and vocational interest requirements ${ }^{1}$ to settle on a small set of compatible careers (circumscription). Subsequently, during emerging adulthood (i.e., ages 15-30 years; Arnett, 2000), people adjust their aspirations from ideal to more realistic (compromise) after experiences that allow them to learn more about their aptitudes ${ }^{2}$ and lifestyle preferences, as well as the compatibility of such aptitudes and lifestyle preferences with the requirements of the careers in their set of acceptable alternatives.

Among Gottfredson's $(1981,2005)$ five facets of potential careers that people routinely consider (viz., gender type, prestige level, vocational interest requirements, ability requirements, and lifestyle requirements), the area of lifestyle requirements (characteristic of a career) and lifestyle preferences (characteristic of an individual) is perhaps the least researched but nonetheless an important aspect. This area is important because career development occurs in the larger context of development over the life course (Levinson, 1978), and lifestyle preferences may change in response to new life circumstances. For example, career exploration characteristic of the period of emerging adulthood generally ends around the same time that people get married (Arnett, 2000; Savickas, 2002, 2005). Afterward, in many cases, a comfortable balance between work and home lives can transform into a dilemma when people become parents, as pressure to devote more time to stabilizing a career coincides with pressure to devote more time to raising children. Of course, many people choose not to raise children, and this choice allows them more freedom in allocating their time.

The heterogeneity in the lifestyle preferences of women in the general population are addressed by Hakim's $(2000,2006)$ empirically based preference theory. It proposes, for example, that women fall into one of three groups along a continuum of commitment to work versus home: Approximately 20\% of women would choose to work full-time regardless of external factors like a spouse's income (this seems to be true for approximately $55 \%$ of men), approximately $60 \%$ of women would work outside the home or be homemakers depending on the circumstances, and the remaining $20 \%$ of women would choose to be homemakers regardless of external factors.

In addition to this heterogeneity in lifestyle preferences among women, gender differences in lifestyle preferences also have been observed. Lifestyle preferences of men and women who do have children may diverge temporarily in response to the childcareversus-career dilemma. Gutmann (1987) argues that women and men handle this dilemma differently, such that women become more dependent and nurturant, focused on their role as caregivers, and men become more detached and self-disciplined, focused on their role as providers. This divergence in personalities may be reflected in gender differences in lifestyle preferences. For example, women's higher commitment to parenting on average and men's higher commitment to work on average (e.g., Greenberger \& O'Neil, 1993) demonstrate one area of lifestyle preferences that could contribute to gender differences in occupational achievement during some of the most productive years (Browne, 2002, 2004-2005; Hakim, 2000, 2006; Pinker, 2008; Rhoads, 2004).
Although gender differences in lifestyle preferences have been observed among the general population, and particularly among parents, less is known about the lifestyle preferences of the subset of the general population who have the potential to make farreaching contributions to STEM. One characteristic that has proven useful for identifying people in this subset is intellectual talent (Park, Lubinski, \& Benbow, 2007, 2008; Wai, Lubinski, \& Benbow, in press). ${ }^{3}$ Indeed, the evidence suggests that intellectually talented groups are the people most likely to develop into eminent contributors to STEM (Murray, 2003). Gender differences in a specific aspect of lifestyle preferences-commitment to work-have been observed among these intellectually talented groups (Lubinski \& Benbow, 2006), but there is more to lifestyle preferences than commitment to work.

The purpose of this research is to add to the existing evidence on lifestyle preferences and orientation of intellectually talented groups by investigating empirically whether gender differences in lifestyle preferences that may contribute to gender differences in

\footnotetext{
${ }^{1}$ One of the largest psychological gender differences observed is in the area of the people versus things dimension of vocational interests (Lippa, 2006), an individual differences variable found in the traditional trait-factor approaches of industrial/organizational and vocational psychology (Armstrong \& Rounds, 2008; Dawis, 1992; Dunnette, 1976; Dunnette \& Hough, 1991, 1992; Rounds \& Tracey, 1990) that influences an individual's behavior in learning and work settings (Dawis, 1992; Holland, 1996; Tyler, 1974). On average, women prefer fields or jobs involving working with people or organic content, whereas men prefer fields or jobs involving working with things or inorganic content (Geary, 1998, 2005; Lippa, 1998, 2005, 2006). Thus, it is likely that, even early in their career development, girls eliminate from consideration fields with an inorganic focus more than they eliminate fields with an organic focus, and boys do the reverse.

${ }^{2}$ Although the genders have comparable levels of general mental ability (Brody, 1992; Jensen, 1998), differences in relative strengths, with women more often demonstrating stronger verbal than mathematical/spatial abilities, and men more often demonstrating stronger mathematical/spatial than verbal abilities, intensify the disparities resulting from the differences in vocational interests (Hedges \& Nowell, 1995; Johnson \& Bouchard, 2007a, 2007b; Park et al., 2007; Strand, Deary, \& Smith, 2006). Indeed, substantial evidence supports the idea that gender differences in ability and interest pattern contribute to the different numbers of men and women in various high-achieving careers (Browne, 2002, 2004-2005; Gottfredson, 1981, 2005; Halpern et al., 2007; Lubinski \& Benbow, 2006; Pinker, 2008; Rhoads, 2004).

${ }^{3}$ The importance of studying high potential populations for STEM is illustrated in a study utilizing a modest criterion for eminence: Recently, a 25-year longitudinal study was published that tracked 2,409 participants identified at age 13 as being in the top $1 \%$ in mathematical ability. Given that the top $1 \%$ of ability comprises over one third of the ability range (e.g., the cutting score for an IQ in the top 1\% is around 137, but IQs can go ove 200), their SAT math (SAT-M) scores at age 13 ranged from 390 to 800 (for benchmarks, an SAT-M of 500 at age 13 represents approximately the top 1 in 200 in mathematical reasoning ability, and a score of 700 represents approximately the top 1 in 10,000). Of the 18 participants who subsequently achieved a tenure-track position at a top 50 U.S. university in a STEM domain (a modest criterion for eminence by any standard), their mean SAT-M score at age 13 was 697 (Park et al., 2007). Moreover, this mean score is an underestimate because many were bumping their heads on the SAT-M ceiling, and two had the top possible score of 800 (the lowest SAT-M score in the group was 580, which was higher than the scores of $60 \%$ of the other participants). See also Park et al. (2008).
} 
occupational achievement also develop among these more selective high-potential groups during emerging adulthood, young adulthood, and parenthood. In Study 1, we examined the workrelated lifestyle preferences of a group of top STEM graduate students while in school in their mid-20s and again 10 years later to determine whether the men's and women's work preferences had changed over time, whether gender differences had emerged over that decade, and whether parenthood was related to the degree of the gender differences in some work preferences. In Study 2, we performed a similar investigation of more general lifestyle preferences and orientation with the age 35 responses of the graduate student participants from Study 1 along with those of a group of high-potential participants selected through a talent search. We examined these preferences for gender differences and also looked at whether the differences varied as a function of parenthood.

\section{Study 1: Work Preferences of Top Math/Science Graduate Students in Their Mid-20s and 10 Years Later}

One way to examine whether individual differences beyond abilities and educational-vocational interests might factor into differential career outcomes is to study high-potential men and women with comparable specific abilities and interests. Although gender differences in longitudinally stable abilities and interests are well documented among the general population (Browne, 2002, 2004-2005; Dawis, 2001; Geary, 1998, 2005; Gottfredson, 1981, 2005; Rhoads, 2004) and highly talented populations (Lubinski \& Benbow, 2006), there are groups for which these gender differences are minuscule.

For example, one study of top math/science graduate students in their mid-20s (Lubinski, Benbow, Shea, Eftekhari-Sanjani, \& Halvorson, 2001) found a remarkable degree of similarity in the men's and women's responses on several well-known measures: the SAT, the Graduate Record Exam, the Adjective Checklist (Gough \& Heilbrun, 1983), the Study of Values (Allport, Vernon, \& Lindzey, 1970), and the Strong Vocational Interest Inventory (Harmon, Hansen, Borgen, \& Hammer, 1994). These graduate students also displayed similar lifestyle preferences, similar amounts of time devoted to studying and research, and similar rates of participation in precollegiate educational opportunities awarded to them as well as those they sought out and experienced, the levels of which indicated considerable commitment to their future careers (Lubinski, Benbow, et al., 2001). Both genders were privileged in terms of the opportunities afforded them for developing expertise in STEM, and they had the ability and interests to take advantage of these opportunities.

In Study 1, these participants were reexamined 10 years after their initial assessment as first- or second-year graduate students attending world-class math/science departments in the United States to determine (a) whether men's and women's work preferences changed over time; (b) whether gender differences in these work preferences emerged during a decade critical for professional development (Ericsson, 1996; Eysenck, 1995; Jackson \& Rushton, 1985; Murray, 2003; Simonton, 1988, 1994, 1999; Zuckerman, 1977), including the years spent completing graduate school and those immediately following acquisition of their terminal degrees; and (c) whether meaningful gender differences varied as a function of parenthood.
Method

\section{Participants}

Participants for Study 1 were drawn from Cohort 5 of the Study of Mathematically Precocious Youth (SMPY; Lubinski \& Benbow, 2006). This group of first- and second-year graduate students attended U.S. math/science departments ranked among the top 15 by Gourman (1989) and the National Research Council (1987). These students (368 men, 346 women) were surveyed in 1992, during their first or second year in graduate school (Lubinski, Benbow, et al., 2001), and were surveyed again in 2003-2004 (275 men, 255 women; Lubinski, Benbow, Webb, \& Bleske-Rechek, 2006). Ratios of men to women in the graduate programs from which they were selected often exceeded 3:1, so women were oversampled at the outset in order to achieve an approximately equal number of participants of each gender (Lubinski, Benbow, et al., 2001). At the time of the 2003-2004 survey, the mean age of the graduate student participants was 35.4 years $(S D=1.7)$, and approximately half of them were parents ${ }^{4}$ (male $n=142$, female $n=132$ ). Eighty-five percent of the graduate student participants were Caucasian, $2 \%$ were African American, 2\% were Hispanic, 9\% were Asian, and 2\% didn't provide their race. Response rates for the assessments analyzed here were greater than $75 \%$.

\section{Measures}

The 1992 and 2003 surveys given to these participants contained items generated by a variety of consultants with different expertise in the basic and applied psychological sciences (see Acknowledgement in Lubinski et al., 2006, pp. 198-199). Consultants were asked to produce items pertaining to work preferences that they thought could bear on career development. For the final survey, a subset of the items (e.g., "Traveling as part of the work I do" or "Working no more than 50 hours per week"; abbreviated versions of all 37 items are found in Figures 1 and 2) was selected to minimize redundancy and maximize breadth. This set of Work Preferences items, rated on a scale ranging from 1 (not important) to 5 (extremely important), was administered to the graduate student participants in 1992 and again in 2003.

\section{Results}

\section{Phase 1: Men's and Women's Changes in Priorities Between Age 25 and Age 35 and Gender Differences in Priorities at Age 25 and Age 35}

To afford the greatest amount of descriptive flexibility and nuance (given the uniqueness of this sample, with similar numbers of each gender), we analyzed gender differences by computing standardized mean differences (Cohen's $d$ ) in the following two ways for each item:

1. The age 35 mean response minus the age 25 mean response was divided by the pooled within-group standard deviation separately for men and women. This effect size indicates how item-level preferences increased or de-

\footnotetext{
${ }^{4}$ Some graduate student participants were already parents at the time of the first survey (male $n=8$, female $n=5$ ).
} 


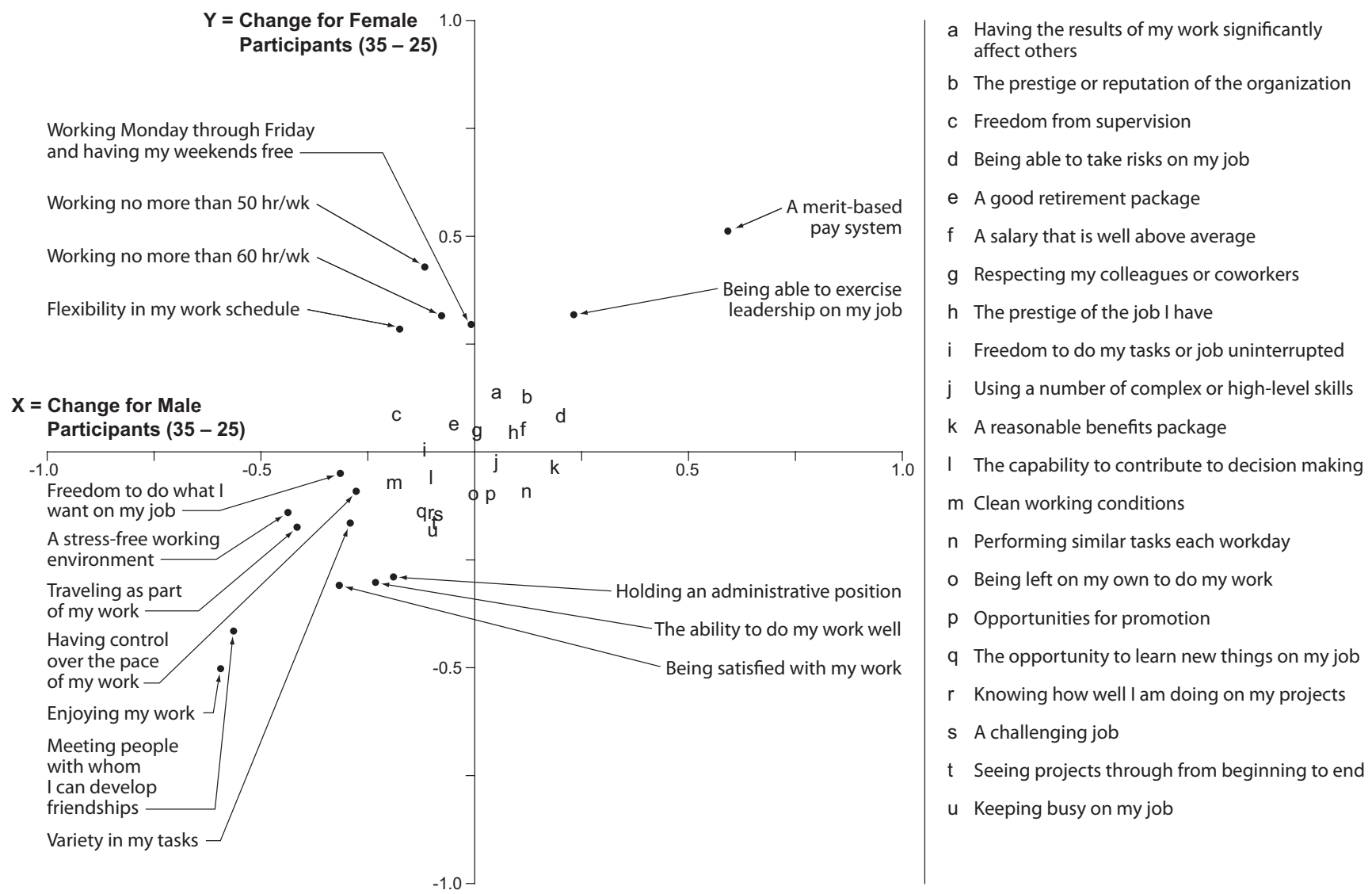

Figure 1. Change in importance of work preferences among top math/science graduate students between age 25 and age 35 by gender. Items that manifested statistically significant $(\alpha<.01)$ changes for men or women or both over time are plotted as points in the figure with abbreviated versions of the items. The items in the legend (labeled $a$ through $u$ ) are those that manifested less change over time. Letters on the plot correspond to the items found in the legend and their respective locations within this space. $35-25$ indicates that the effect size for each item in this figure was computed with the age 35 mean minus the age 25 mean in the numerator. The effect size that this numerator (rather than a numerator of the age 25 mean minus the age 35 mean) yields is positive when that particular item became more important over time, and is negative when that item became less important over time. For all $|d|>0.22, p<.01$

creased in importance over the 10-year period within gender (positive values indicate increases; negative values indicate decreases; plotted in Figure 1).

2. The male mean response minus the female mean response was divided by the pooled within-group standard deviation at each of the two time points. This effect size indicates the gender difference in the importance of itemlevel preferences at each time point (positive values indicate an item is more important for men than for women; negative values indicate an item is more important for women than for men; plotted in Figure 2).

Figure 1 shows the graduate students' change in work preferences between their mid-20s and mid-30s by gender. After computing the age 35-minus-age 25 standardized mean difference for each item for men and women separately, we plotted one point for each item on Cartesian coordinates $(X=$ standardized change in mean importance for men over time, $\mathrm{Y}=$ standardized change in mean importance for women over time). To the extent that a point fell in the southwest (SW) or northeast (NE) quadrants, the importance of a preference decreased or increased over time for both women and men. Points that fell in the northwest (NW) quadrant represented work preferences that increased in importance for women and decreased in importance for men. Similarly, points that fell in the southeast (SE) quadrant represented work preferences that increased in importance for men over time and decreased in importance for women.

Many work preferences did not noticeably change in importance over time for either men or women, for example, receiving a good retirement package, respecting colleagues, and using complex or high-level skills at work. Several preferences did change in importance over time, however. Leadership on the job and meritbased pay increased in importance for both men and women, and satisfaction with work, enjoyment of work, and friendships at work all decreased in importance between age 25 and age 35. Also of note, the importance of flexible work schedules and limited work 

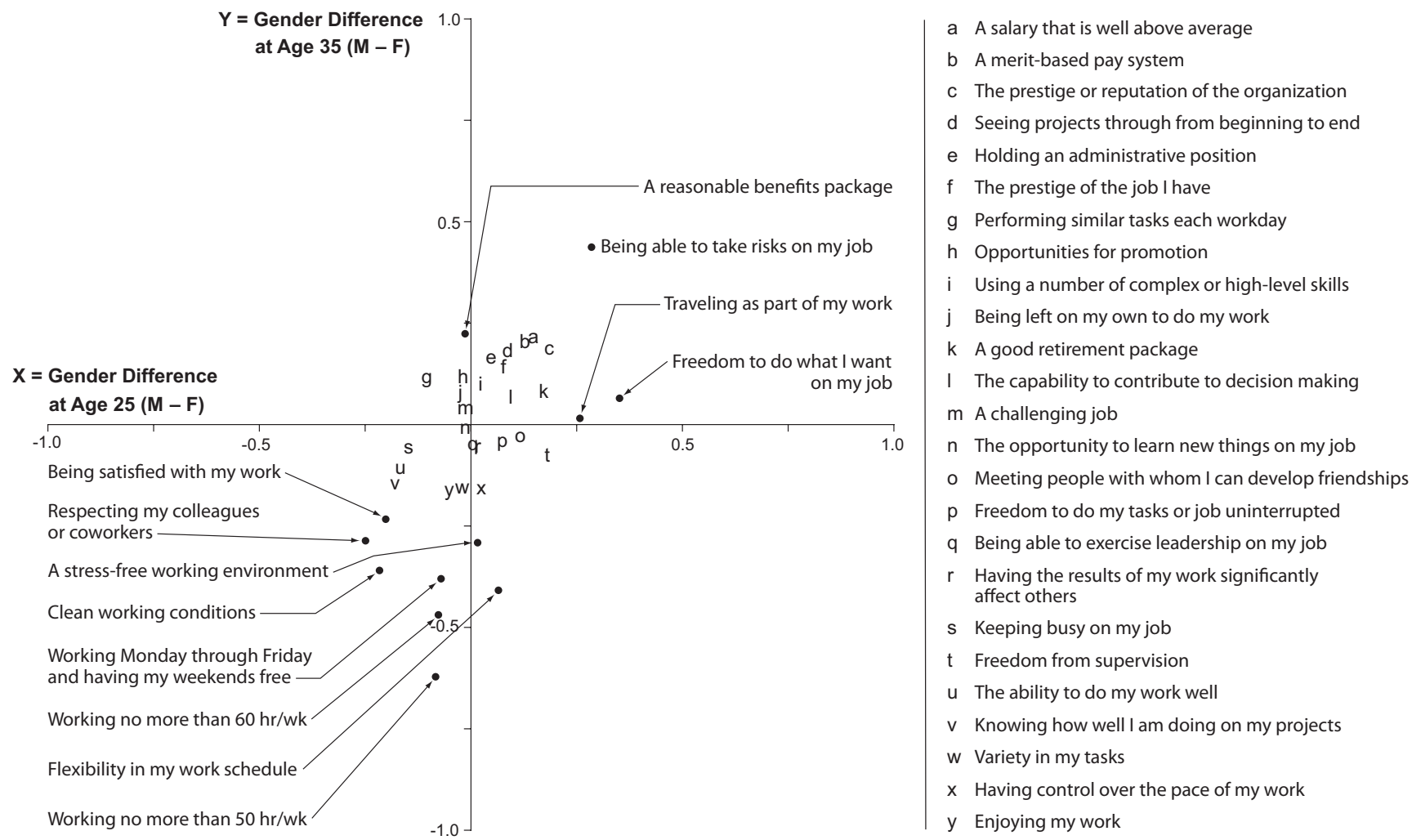

Figure 2. Gender differences in importance of work preferences at age 25 and age 35 among top math/science graduate students. Items about work preferences that manifested statistically significant $(\alpha<.01)$ gender differences at one or both time points are plotted with abbreviated item descriptors. Items plotted as letters manifested relatively little difference between the genders at both time points and correspond to the items found in the legend. $\mathrm{M}-\mathrm{F}$ indicates that the effect size for each item in this figure was computed with the male students' mean minus the female students' mean in the numerator. The effect size that this numerator (rather than a numerator of the female students' mean minus the male students' mean) yields is positive when a particular item is more important for male students than for female students, and is negative when that item is more important for female students than for male students. For all $|d|>0.22, p<.01$.

hours increased for women but not appreciably for men. (Means, standard deviations, and confidence intervals for the effect sizes plotted in Figures 1 and 2 are available in the online Supplemental Material, Tables S1 and S2.)

Figure 2 shows the gender differences among the graduate students in various work preferences and the temporal trajectories of these gender differences. We computed the men-minus-women standardized mean difference for each item at each time point and then plotted one point for each item on Cartesian coordinates $(\mathrm{X}=$ Time 1, at age 25; Y = Time 2, at age 35). To the extent that each point fell in the SW or NE quadrant, the direction of the effect was replicated (i.e., items in the SW quadrant are those for which women had a higher mean at both time points, and items in the NE quadrant are those for which men had a higher mean at both time points). To the extent that each point fell on an imaginary $45^{\circ}$ line running through the origin, the magnitude of the effect was stable over time.

The large number of items in the legend indicates that the genders were similar on a variety of work-related preferences: They placed commensurate value on having their work significantly affect the lives of other people, on a challenging job, and on opportunities to learn new things. The plot shows that there were also some moderate gender differences at both time points: Men placed greater value on taking risks at work, salary, and the prestige of the organization (see the cluster of Items a-c, a consistent if not statistically significant trend), whereas women, relative to men, placed greater emphasis on being satisfied with the work they do, respecting coworkers, and clean working conditions. There was, in addition, a noteworthy increase in gender differences over time for flexibility in work schedule, for limiting the amount of time devoted to work, and for being free on weekends: By their mid-30s, women placed greater emphasis on these aspects of work than men did, and these gender differences were negligible or nonexistent 10 years earlier. These results correspond with those of Figure 1. For some items, the men and women responded similarly at age 25 , but their responses diverged somewhat 10 years later.

\section{Phase 2: Differences in Priorities Among Men and Women With and Without Children at Age 35 With a Retrospective Comparison}

In addition, we considered how the patterns for a subset of these items changed as a function of parenthood (see Figure 3). In order 


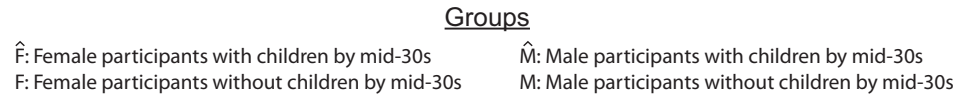

Top Graduate Students in Their Mid-20s Working Monday through Friday and having my weekends free

\begin{tabular}{|c|c|c|}
\hline Extremely important & $\hat{\mathbb{M}} \hat{\mathbf{A}}$ & Effect Size (d) \\
\hline Extremely important & & $\hat{\mathrm{M}}-\mathrm{M}: \quad 0.18$ \\
\hline Very important & $F \hat{M} \bar{F}$ & $\hat{F}-F: \quad 0.27$ \\
\hline Important & $M F \quad \hat{M F}$ & $\hat{\mathrm{M}}-\hat{\mathrm{F}}:-0.12$ \\
\hline Somewhat important & $\hat{F} \quad \hat{M} F \quad M$ & $M-F:-0.03$ \\
\hline Not important & $\hat{M M} M F$ & \\
\hline
\end{tabular}

Flexibility in my work schedule

\begin{tabular}{|c|c|c|}
\hline Extremely important & $\hat{M} \hat{F} \hat{F} \quad M$ & $\frac{\text { Effect Size }(d)}{\hat{\mathrm{M}}-\mathrm{M}:-0.13}$ \\
\hline Very important & $M \hat{F} \hat{M}$ & $\hat{F}-F: 0.01$ \\
\hline Important & 角 $\ldots$ & $\hat{\mathrm{M}}-\hat{\mathrm{F}}:-0.02$ \\
\hline Somewhat important & $\hat{M} \hat{M} F$ & $M-F: \quad 0.13$ \\
\hline Not important & $\mathbb{M} / \hat{F M}$ & \\
\hline
\end{tabular}

Working no more than $\mathbf{5 0}$ hours per week

\begin{tabular}{|c|c|c|}
\hline Extremely important & $M \hat{A N}$ & Effect Size $(d)$ \\
\hline Very important & $M . \widehat{M}$ & $\hat{\mathrm{M}}-\mathrm{M}: \quad 0.08$ \\
\hline Important & $\hat{M E} \quad M \hat{F}$ & $\hat{\mathrm{F}}-\mathrm{F}: \quad 0.25$ \\
\hline Somewhat important & $\hat{M} \hat{F} M F$ & $\hat{M}-\hat{F}:-0.11$ \\
\hline Not important & $\hat{M}$ & M-F: 0.05 \\
\hline & & \\
\hline
\end{tabular}

Working no more than 60 hours per week

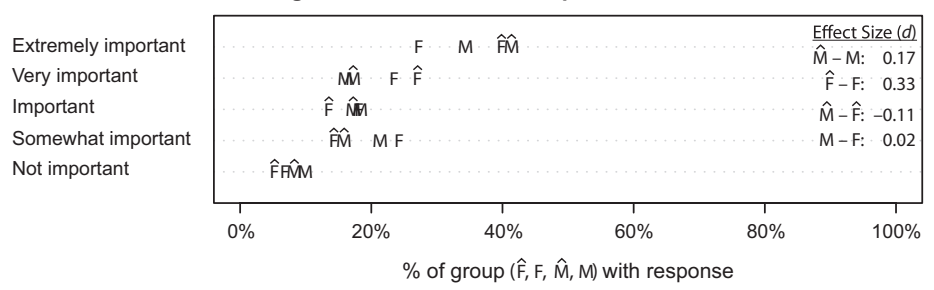

Top Graduate Students in Their Mid-30s Working Monday through Friday and having my weekends free

\begin{tabular}{|c|c|}
\hline & Effect Size (d) \\
\hline$M A A-F$ & $\hat{\mathrm{M}}-\mathrm{M}: \quad 0.08$ \\
\hline MM $F \bar{F}$ & $\hat{F}-F: \quad 0.40$ \\
\hline MÂF & $\hat{M}-\hat{F}:-0.55$ \\
\hline$\hat{F} \quad F \hat{M M}$ & $M-F:-0.25$ \\
\hline$\hat{F} \quad F \quad \hat{M}$ & \\
\hline
\end{tabular}

Flexibility in my work schedule

\begin{tabular}{|c|c|}
\hline $\mathrm{M} \hat{\mathrm{M}}$ & Effect Size (d) \\
\hline IM IM r & $\hat{\mathrm{M}}-\mathrm{M}: \quad 0.13$ \\
\hline $\begin{array}{r}\text { NWF } \\
\hat{A} \text {. }\end{array}$ & $\hat{F}-F: \quad 0.25$ \\
\hline$\hat{F} \cdot F \hat{M} M$ & $\hat{\mathrm{M}}-\hat{\mathrm{F}}:-0.47$ \\
\hline$\hat{F} \quad \hat{H M} \quad M$ & $M-F:-0.37$ \\
\hline$\hat{F} \hat{M M} \ldots$ & \\
\hline
\end{tabular}

Working no more than $\mathbf{5 0}$ hours per week

\begin{tabular}{|r|r|}
\hline$M \quad \hat{M} F$ & $\frac{\text { Effect Size }(d)}{\hat{M}-M: 0.21}$ \\
$\hat{M M} \hat{F} F$ & $\hat{F}-F: 0.79$ \\
$\hat{F} \hat{F} \quad \hat{M}$ & $\hat{M}-\hat{F}:-0.94$ \\
$\hat{F} \quad \hat{M} F M$ & $M-F:-0.36$ \\
$\hat{F} \quad F \quad \hat{M} M$ & \\
\hline
\end{tabular}

Working no more than 60 hours per week

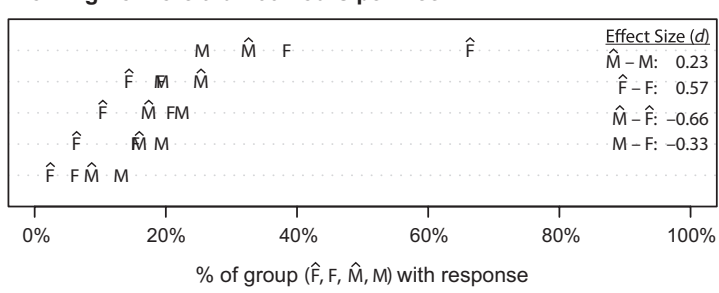

Figure 3. Frequency distributions of math/science graduate students' responses to items about work preferences. For all $|d|>0.33, p<.01$.

to present the clearest picture of the trends underlying Figures 1 and 2, first we separated the participants into four groups (by gender and whether those of each gender had children or not) on the basis of their 2003-2004 survey responses. Then, for this time point, and for the one 10 years earlier, we plotted frequency distributions of these four groups' responses to a subset of Work Preferences items that revealed salient differences at age 35 . These items - working Monday through Friday and having weekends free, flexibility in work schedule, working no more than $50 \mathrm{hr}$ per week, and working no more than $60 \mathrm{hr}$ per week-not only became more important for women and stayed the same or decreased in importance for men from Time 1 to Time 2, but also were among the items showing the largest gender differences at Time 2. We present these distributions this way to show the participants' responses before and after the parent groups had children. In addition, we computed the standardized mean difference in the following four ways for each item:

1. The mean response of men with children minus the mean response of men without children was divided by their pooled within-group standard deviation (denoted by $\hat{M}-M$ : positive values indicate an item is more important for men with children than it is for men without children; negative values indicate an item is more important for men without children than it is for men with children).

2. The mean response of women with children minus the mean response of women without children was divided by their pooled within-group standard deviation (denoted by $\hat{F}-F$ : positive values indicate an item is more important for women with children than it is for women without children; negative values indicate an item is more important for women without children than it is for women with children).

3. The mean response of men with children minus the mean response of women with children was divided by their 
pooled within-group standard deviation (denoted by $\hat{M}-\hat{F}$ : positive values indicate an item is more important for men than it is for women; negative values indicate an item is more important for women than it is for men).

4. The mean response of men without children minus the mean response of women without children was divided by their pooled within-group standard deviation (denoted by $M-F$ : positive values indicate an item is more important for men than it is for women; negative values indicate an item is more important for women than it is for men).

Although the differences between groups were small in the participants' mid-20s (see Figure 3, left column), the women with children rated these items more important in their mid-30s than the rest of the participants did (see Figure 3, right column). Of the differences between all the groups when participants were in their mid-30s, the responses of the male and female parents differed from each other most, and those of the men with and without children were most similar. That more than $50 \%$ of the women with children rated working fewer than $50 \mathrm{hr}$ or $60 \mathrm{hr}$ per week extremely important in their mid-30s is particularly striking, especially when they are compared with the other groups: Fewer than $20 \%$ of the remaining three groups rated working fewer than $50 \mathrm{hr}$ per week extremely important. The proportions of people responding extremely important for one or more, two or more, three or more, or all four items are presented in Table 1. While women with and without children were more likely to rate these items extremely important than did their male counterparts, again women with children stood out: Two-thirds of these women rated at least one of these four items extremely important, and $13 \%$ rated all four of these items extremely important; in contrast, less than half of the participants in the other groups rated at least one item extremely important, and less than $4 \%$ of the participants in the other groups considered all four items to be so.

\section{Discussion}

It is important to discuss these findings in the context of what is already known about this sample (Lubinski \& Benbow, 2006;

Table 1

Proportion of Graduate Students, by Gender and Parenthood Status, Responding That Work Preferences Items Were Extremely Important

\begin{tabular}{|c|c|c|c|c|}
\hline \multirow{2}{*}{$\begin{array}{l}\text { Number of items } \\
\text { rated extremely } \\
\text { important }\end{array}$} & \multicolumn{2}{|c|}{ Men } & \multicolumn{2}{|c|}{ Women } \\
\hline & $\begin{array}{l}\text { Without } \\
\text { children }\end{array}$ & $\begin{array}{l}\text { With } \\
\text { children }\end{array}$ & $\begin{array}{l}\text { Without } \\
\text { children }\end{array}$ & $\begin{array}{l}\text { With } \\
\text { children }\end{array}$ \\
\hline 0 & $65(100)$ & $58(100)$ & $52(100)$ & $32(100)$ \\
\hline 1 & $22 \quad(35)$ & 21 (42) & $22(48)$ & $13(68)$ \\
\hline 2 & $8 \quad(13)$ & 11 (21) & 12 (26) & $23 \quad(55)$ \\
\hline 3 & $4 \quad(5)$ & 7 (10) & 11 (14) & 19 \\
\hline 4 & $1 \quad$ (1) & $3 \quad(3)$ & $3 \quad(3)$ & 13 (13) \\
\hline
\end{tabular}

Note. Cumulative percentages are presented in parentheses. Items included (a) working Monday through Friday and having weekends free, (b) flexibility in work schedule, (c) working no more than $50 \mathrm{hr}$ per week, and (d) working no more than $60 \mathrm{hr}$ per week.
Lubinski, Benbow, et al., 2001; Lubinski et al., 2006). For example, there is evidence to suggest that the selection processes implemented by the graduate schools that secured the participants in this study were effective (Lubinski, Benbow, et al., 2001): These top math/science graduate student participants had exceptional talent and passion for their fields, and during junior high and high school they had sought out opportunities to develop expertise in STEM. Moreover, the men and women did not differ significantly in the proportion eventually securing tenure-track positions at top U.S. universities. Hence, the graduate schools surveyed did indeed identify men and women who held promise for leadership in STEM and developed their talents in seemingly equally effective ways, as judged by tenure-track positions. Within this sample, however, men and women did differ significantly in the proportion of each who chose to become homemakers: $1 \%$ and $9 \%$, respectively - a ratio of 9 to 1 (Lubinski et al., 2006). The latter subset and the general tendencies uncovered in this study need to be taken into account in future work on gender disparities. Additionally, because the women in this group were underrepresented relative to men in these programs, these women are even more uncommon among women in general than the men in this sample are among men in general in their level of commitment to and ability to be involved in STEM.

With this background, several observations can be made from the pattern of their responses to items about work preferences. First, it is clear that the men and women considered many preferences to be similarly important and of constant importance over time. These preferences include having the results of their work significantly affect others, using a number of complex or highlevel skills in their work, being able to contribute to decision making at work, and having freedom to do their work uninterrupted. This result might have been expected, given the similarity of the genders in their personality and abilities in their mid-20s (Lubinski, Benbow, et al., 2001).

Second, some priorities changed similarly over time for men and women. These changes seem to indicate maturation, or the shift from emerging adulthood to young adulthood that involves becoming a more productive member of society (Arnett, 2000; Caspi, Roberts, \& Shiner, 2005). Leadership opportunities and meritbased pay became more important, while satisfaction, friendships, and enjoyment, at least in the workplace, became less so, suggesting that these aspects of life, while they may be important outside of work, are not as important in work settings by the participants' mid-30s as they were 10 years earlier. While at age 25 these participants were focused on their education and finding their niche, at age 35 they were more focused on making their mark (Levinson, 1978; Savickas, 2002).

Third, some gender differences in work preferences remained largely stable over time and may represent general gender differences in the responsiveness to extrinsic versus intrinsic rewards of a job (Browne, 2002; Dawis, 2001; Pinker, 2008; Rhoads, 2004); that is, men placed more value on high salaries, taking risks (consistent with the findings of Byrnes, Miller, \& Schafer, 1999), and the prestige of their organization, whereas women placed more value on satisfaction at work, respecting colleagues, and clean conditions in the workplace.

Finally, parenthood was related to work preferences, especially for women: Women who 10 years earlier, before they had become mothers, placed the same amount of importance on short hours and 
flexible schedules as everyone else did, rated these things as much more important after motherhood. This phenomenon has been observed cross-culturally in normative samples (Geary, 2000), but that this change in preferences was found among even some of the most talented and passionate young women in STEM could add nuance to our understanding of why men are overrepresented in high-achieving positions in STEM fields: A subset of those women with the talent and passion to work long hours in order to succeed at high levels in STEM appear to have priorities coming online along with motherhood that make them want to reduce their work hours, take a leave of absence from work, or exit their careers altogether to become homemakers, consistent with Gutmann (1987).

The choices available to mothers in STEM are many, and they fall into three categories: remain in STEM, choose another field, or exit the work force altogether. Given the investment they have already made in their education, many women probably choose to remain in STEM, and even within STEM, there are a number of ways to care for their children and still develop their careers. If women become mothers during graduate school, it is likely that the flexibility of this period will accommodate their desire to be primary caregivers. After graduate school, women can continue to work full-time and delegate child rearing to a spouse or other caregiver, reduce their hours in their current track, switch to another job within STEM that is less demanding of their time, or take a temporary leave of absence. With the exceptions of continuing to work full-time while delegating child rearing, which many women prefer not to do (Browne, 2002; Hakim, 2000, 2006; Rhoads, 2004), and to a lesser extent having children during graduate school, all of the options available to STEM women with children result in a slowdown in their career development relative to the career development of childless women and of men.

In addition, while taking a temporary leave of absence sounds like an option that allows both child rearing and career development, albeit with a short delay, doing so while remaining at the forefront of one's field is especially difficult in STEM fields relative to social sciences and humanities fields as a result of discipline differences in the durability of knowledge (McDowell, 1982); that is, conceptual and technical knowledge turnover rates are higher in engineering and the physical sciences than in the social sciences and humanities. ${ }^{5}$ Consequently, the appreciable number of women who might have succeeded at high levels in STEM fields but preferred not to sacrifice their overall career development while caring for their children might gravitate toward fields in academia where they won't be as severely delayed in their career development for taking time off to raise children-fields and disciplines wherein not as much catching up is needed as in STEM. Indeed, with respect to high-level STEM positions, it is hard to catch up when one is competing with intellectual peers who work $60+$ hours per week and who have never been on leave. Returning to work is not the issue; rather, it is returning to work at the same level that is the focal issue.

Furthermore, when such changes in priorities occur among women whose partners earn high incomes, acting on these changes becomes more feasible. For example, there is evidence that assortative mating among highly intelligent people has the consequence that women who would otherwise be eligible for careers in the highest echelons pull out of the labor force at rates higher than comparable men do, because their husbands' incomes are suffi- cient for the lifestyle they would like to maintain as a couple (Becker \& Lindsay, 2004). Thus, this change in work preferences among women with the capacity to make an impact in STEM may result in more women leaving STEM than initially seems likely.

This study focuses on people in young adulthood, a period in the life course when parenting is at its highest importance and career development is most intense among those aiming for exceptional achievement, impact, and position in STEM (Ericsson, 1996; Eysenck, 1995; Jackson \& Rushton, 1985; Murray, 2003; Simonton, 1988, 1994, 1999; Zuckerman, 1977). Gutmann (1987) contended that the divergence in personalities in response to parenthood is a temporary one and that as children grow and parents approach midlife, the personalities of men and women converge, with men taking on more caring characteristics and women taking on more independent characteristics. Helson, Pals, and Solomon (1997) found considerable empirical support for this hypothesis among three longitudinal studies of personality over the life course, with the caveats that cohort effects seemed to be present and that none of the studies included a "cohort in which there was not a distinct gender-related division of labor in young adulthood" (p. 308). Future studies with this cohort of graduate students should address whether the gender differences in work preferences that have been observed here indeed peak during young adulthood (and especially during parenthood) and subsequently diminish.

Study 2: Life Values, Personal Views, and Life Satisfaction of Top Math/Science Graduate Students and the Profoundly Gifted in Their Mid-30s

In Study 2, a second group of participants with extraordinary potential for educational and occupational achievement were analyzed for replication along with the graduate student sample utilized in Study 1. Utilizing this additional sample captured many of the components of a constructive replication (Lykken, 1968, 1991), because it represents a way of identifying another exceptional high-potential population with measures and methods different from those used to identify the sample of graduate students. This second group was a sample of profoundly gifted participants (top 1 in 10,000) identified by age 13 and tracked for 20 years. They and the graduate student participants from Study 1 both completed assessments of their life values and personal views when they were in their mid-30s. This profoundly gifted cohort, too, experienced an opportunity-rich environment in terms of encouragement to excel academically and intellectually. Through their talent search experience and subsequent counseling, they received much encouragement based in part on objective information about their abilities and potential (Benbow, Lubinski, \& Suchy, 1996; Lubinski, Webb, Morelock, \& Benbow, 2001). We compared these assessments of the life values and personal views of these two cohorts of exceptionally talented young adults to answer the following questions: Where, if at all, do we find gender differences in preferences and psychological orientation at age 35 that could contribute to gender differences in achievement, development,

\footnotetext{
${ }^{5}$ When considered jointly, ability pattern, interests, and commitment to work (Lubinski \& Benbow, 2006), coupled with the rapid information decay for cutting-edge STEM expertise (McDowell, 1982), can explain, in part, why women are overrepresented in some areas like psychology and veterinary medicine (Pinker, 2008).
} 
and orientation toward the world of work, and second, do these differences vary as a function of parenthood? In addition, we considered individual differences in the participants' life and career satisfaction and explored the degree to which they were associated with gender and parenthood for these two highly talented and opportunityadvantaged populations.

\section{Method}

\section{Participants}

The graduate students from Study 1 were also participants in this study. Talent search participants from SMPY's Cohort 3, identified in the early 1980 s as representing the top 1 in 10,000 in cognitive abilities (SAT-M $\geq 700$ or SAT-V $\geq 630$ by age 13 ), were surveyed in 2003 (Lubinski et al., 2006). The talent search participants' mean age was 33.3 years $(S D=1.2)$, and $94(35 \%)$ of the men and $28(33 \%)$ of the women had become parents by 2003. Sixty-five percent of the talent search participants were Caucasian, $1 \%$ were African American, $17 \%$ were Asian, and 1\% were of another ethnic background. Sixteen percent did not disclose their race. Response rates for both cohorts for the assessments analyzed here were greater than $75 \%$.

\section{Measures}

Life Values and Personal Views. The consultants who provided items for Study 1 simultaneously provided items on life values and personal views that they thought could be relevant to career development. Again items were selected to minimize redundancy and maximize breadth.

The sets of Life Values and Personal Views items were administered to both the graduate students and the talent search participants in 2003. Life Values items (e.g., "Being politically active in my community" and "Living close to my parents"; abbreviated versions of these 28 items are found in Figure 4) were scaled from 1 (not important) to 5 (extremely important), and Personal Views items (e.g., "I want to improve the human condition" and "I want to be recognized as the best in my field"; abbreviated versions of these 23 items are found in Figure 5) were scaled from 1 (strongly disagree) to 5 (strongly agree).

Satisfaction. Here we were interested in assessing participants' satisfaction with their careers and their lives overall. Career satisfaction was measured with one Likert-type item ("How satisfied are you with the current direction of your professional career?") on a scale ranging from 1 (very dissatisfied) to 7 (very satisfied). We examined the participants' life satisfaction with the five-item Satisfaction With Life Scale (Pavot \& Diener, 1993) as a function of gender and

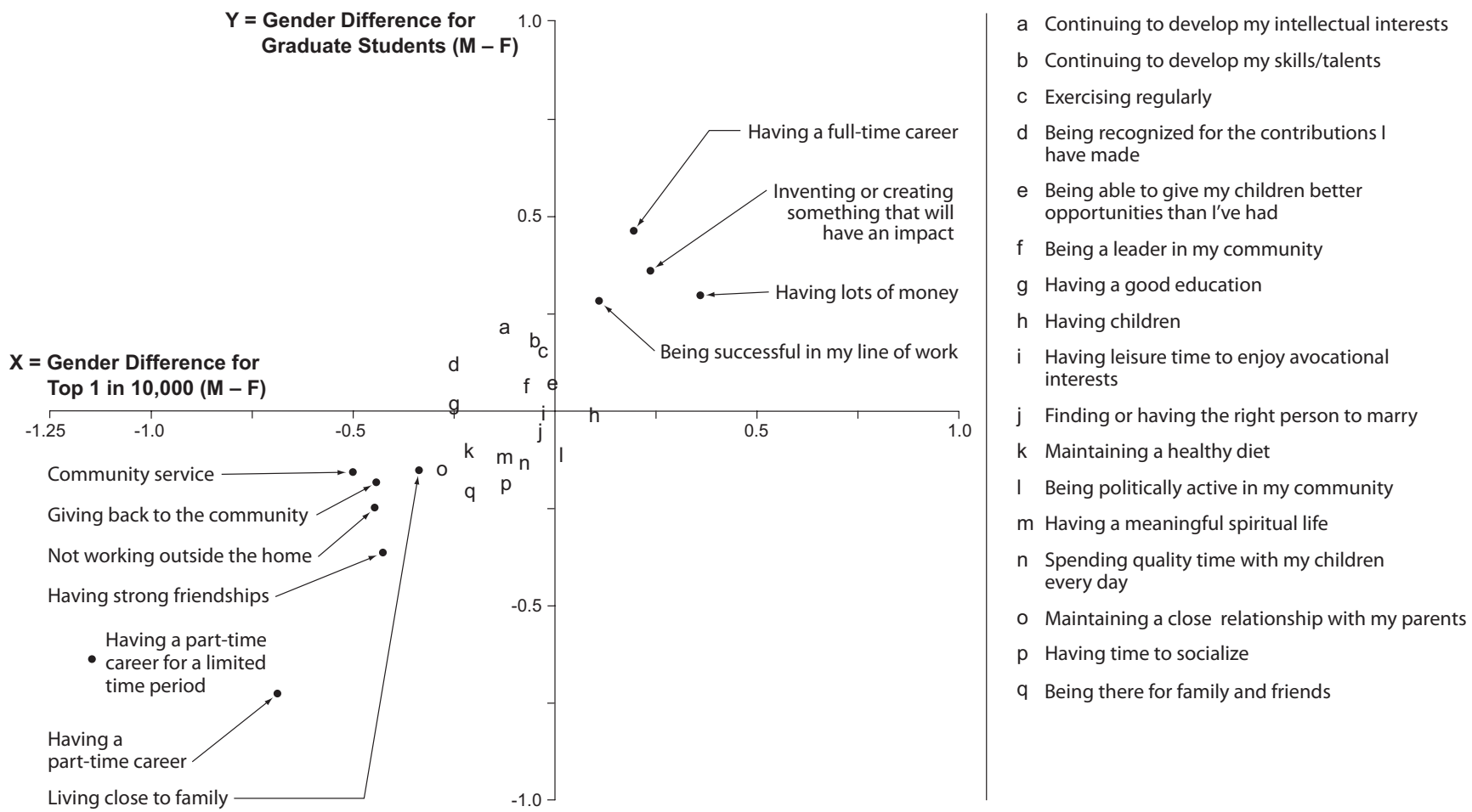

Figure 4. Gender differences in importance of life values among top math/science graduate students and top 1 in 10,000 talent search participants in their mid-30s. M - F indicates that the effect size for each item in this figure was computed with the male participants' mean minus the female participants' mean in the numerator. The effect size that this numerator (rather than a numerator of the female participants' mean minus the male participants' mean) yields is positive when a particular item is more important for male participants than for female participants, and is negative when that item is more important for female participants than for male participants. For all graduate students, $|d|>$ $0.22, p<.01$, and for all talent search participants, $|d|>0.30, p<.01$. 


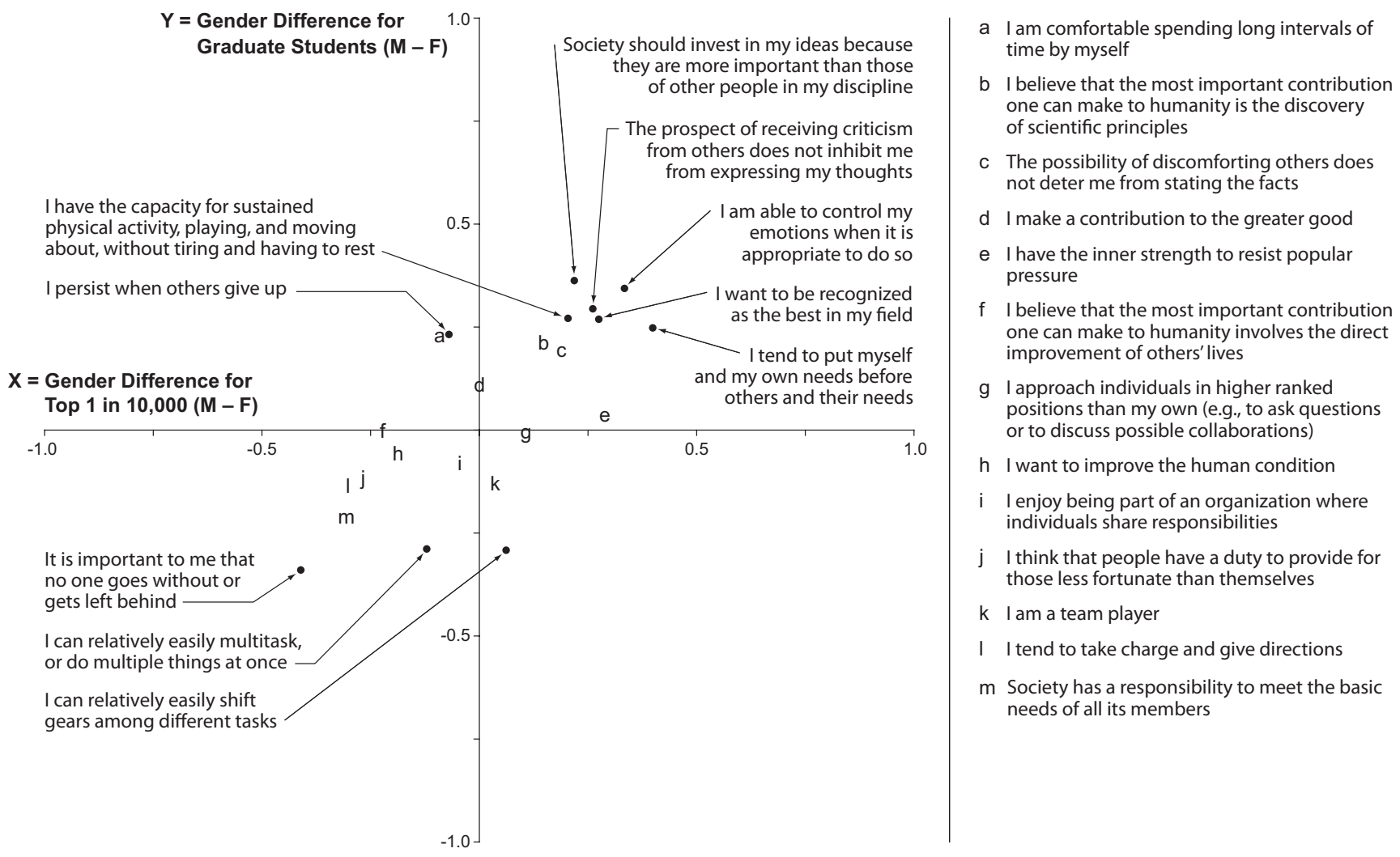

Figure 5. Gender differences in agreement with statements about personal views among top math/science graduate students and top 1 in 10,000 talent search participants in their mid-30s. M - F indicates that the effect size for each item in this figure was computed with the male participants' mean minus the female participants' mean in the numerator. The effect size that this numerator (rather than a numerator of the female participants' mean minus the male participants' mean) yields is positive when a particular item is more important for male participants than for female participants, and is negative when that item is more important for female participants than for male participants. For all graduate students, $|d|>0.22, p<.01$, and for all talent search participants, $|d|>0.35, p<.01$.

parenthood. Cronbach's $\alpha=.83$ for the graduate student participants, and $\alpha=.91$ for the profoundly gifted participants.

A Levene test revealed significant between-group heterogeneity of variance in life satisfaction among the profoundly gifted talent search participants only, $F(3,331)=4.90, p<.002$, with larger variances among the participants without children (see Table 2). Because twoway analyses of variance (ANOVAs) often exhibit excessive Type I error rates and inadequate power with heterogeneous variances and unequal sample sizes (Maxwell \& Delaney, 2004), we performed a generalized Welch approximate degrees of freedom (ADF; Lix \& Keselman, 1995) test to assess group differences among the talent search participants on this measure. ADF tests do not assume equality of population variances across groups, and their Type I error rates and power are generally better than those of ANOVAs under heterogeneity of variance (Lix \& Keselman, 1995).

\section{Results}

Phase 1: Gender Differences in Life Values and Personal Views of Graduate Students in Their Mid-30s, Replicated With the Profoundly Gifted

The Life Values (see Figure 4) and Personal Views (see Figure 5) items were administered to both cohorts during their mid-30s.
We calculated the men-minus-women $d$ (with the pooled withingender standard deviation in the denominator) for each item within each cohort to explore gender differences, and we also examined the extent to which the findings on these indicators among the profoundly gifted replicated those among the graduate student participants to ascertain their generalizability to a different highpotential population.

Figures 4 and 5 show age 35 findings from the graduate student and profoundly gifted samples and illustrate the extent to which findings from one cohort are replicated in the other. Both plots of bi-cohort (men-minus-women) effect sizes illustrate replications $(\mathrm{X}=$ profoundly gifted, $\mathrm{Y}=$ graduate students $)$ : For each point that falls in either of the SW or NE quadrants, the direction of the effect for a single item was replicated across cohorts (i.e., items in the SW quadrant are those for which women had a higher mean in both cohorts, and items in the NE quadrant are those for which men had a higher mean in both cohorts). Further, to the extent that the point falls on an imaginary $45^{\circ}$ line running through the origin, the magnitude of the effect was also replicated.

Figure 4 shows the effect sizes from both cohorts for the Life Values items. Again, the genders rated a wide variety of items similarly, including finding the right person to marry, being able to give their children better opportunities than they had, and having 
Table 2

Life Satisfaction and Career Satisfaction for Graduate Student (GS) and Talent Search (TS) Participants by Gender and Parenthood Status

\begin{tabular}{|c|c|c|c|c|}
\hline \multirow[b]{2}{*}{ Variable } & \multicolumn{2}{|c|}{ GS } & \multicolumn{2}{|c|}{ TS } \\
\hline & $\operatorname{Men}^{\mathrm{a}}$ & Women $^{\text {b }}$ & $\operatorname{Men}^{c}$ & Women $^{\mathrm{d}}$ \\
\hline \multicolumn{5}{|c|}{ Life satisfaction } \\
\hline \multicolumn{5}{|l|}{ Without children } \\
\hline Mean outcome & 25.1 & 24.5 & 24.2 & 22.8 \\
\hline$S D$ & 4.6 & 4.6 & 7.5 & 6.6 \\
\hline \multicolumn{5}{|l|}{ With children } \\
\hline Mean outcome $e^{\mathrm{e}}$ & 27.0 & 28.2 & 26.8 & 30.0 \\
\hline$S D$ & 4.4 & 4.2 & 5.6 & 4.6 \\
\hline \multicolumn{5}{|c|}{ Career satisfaction ${ }^{\mathrm{f}}$} \\
\hline Without children & 60 & 57 & 55 & 61 \\
\hline With children & 76 & 71 & 66 & 64 \\
\hline
\end{tabular}

${ }^{\text {a }}$ Minimum $n$ : Without children $=111$; With children $=133 . \quad{ }^{\mathrm{b}}$ Minimum $n$ : Without children $=113$; With children $=118 .{ }^{\mathrm{c}}$ Minimum $n$ : Without children $=147 ;$ With children $=83 .{ }^{\mathrm{d}}$ Minimum $n$ : Without children $=$ 54 ; With children $=26$. ${ }^{\mathrm{e}}$ Range $=5-35$, where $20=$ neutral and $35=$ happiest. ${ }^{\mathrm{f}}$ Percentage of participants who were satisfied or very satisfied with career.

leisure time to enjoy avocational interests. There were also some salient gender differences in ratings, however. Women from both cohorts relative to men placed more importance on part-time work and having a part-time career for a limited period of time, having strong friendships, giving back to the community, and living close to family; conversely, men placed more emphasis on having a full-time career, creating or inventing something that will have an impact, and monetary wealth.

We observed further nuances in the differences and similarities in men's and women's views (see Figure 5). Women felt more strongly than men that no one goes without or gets left behind. Men, on the other hand, were distinguished in the amount of importance they placed on their ideas, being recognized as the best in their respective fields, and putting their needs above those of others. (Means, standard deviations, and confidence intervals for the effect sizes plotted in Figures 4 and 5 are available in the online Supplemental Material, Tables S3 and S4.)

\section{Phase 2: Differences in Life Values and Personal Views Among Graduate Student Men and Women With and Without Children at Age 35, Replicated With the Profoundly Gifted}

We again calculated means and $d$ s for both genders as a function of parenthood status. For replication with Study 1, we present dot plots for four work-related items that are conceptually similar to those presented in Phase 2 of Study 1 (see Figure 6). For comprehensiveness, we have included the remaining plots in the online Supplemental Material (see Figures S1 and S2). Figures 6 and S1 present dot plots of the graduate students' and profoundly gifted participants' responses to Life Values items that manifested noteworthy differences across gender and parenthood status. Again, the differences were largest between the male and female parents (denoted by $\hat{M}-\hat{F}$ ), particularly when it came to the importance of full- versus part-time work. Almost $40 \%$ of women with children in both cohorts reported that having a part-time career was important, very important, or extremely important, while less than $15 \%$ of men with children reported that to be true. Moreover, $23 \%$ of the graduate student women with children and $38 \%$ of the profoundly gifted women with children reported that full-time work was not important to them. In contrast, only $6 \%$ of the graduate student men (with and without children) and $15 \%$ of the profoundly gifted men agreed. Also note the responses of the women without children. In many cases, their responses were more similar to those of the men than they were to those of the women with children. Finally, the patterns of responses manifested by the graduate student cohort were replicated by the profoundly gifted group.

We broke down the patterns of responses to some Personal Views items by gender and parenthood status for the dot charts in Figure S2. The differences among the groups for these items were altogether smaller than for the items we explored in Figures 3, 6, and $\mathrm{S} 1$, but again, the largest differences were between the men and women with children. Men with and without children responded similarly to almost every item presented, as did the graduate student women with and without children; however, the profoundly gifted women without children responded to three of the four items more like the men did than like the women with children did: "Society should invest in my ideas because they are more important than those of other people in my discipline," "I want to be recognized as the best in my field," and "I can relatively easily multitask." Women with children also stood out in their responses to several items. They agreed more than the other groups that "it is important that no one goes without or gets left behind," and the profoundly gifted women with children reported more than the other groups in their cohort did that they can "easily multitask."

\section{Phase 3: Life Satisfaction and Career Satisfaction of Graduate Student Men and Women With and Without Children at Age 35, Replicated With the Profoundly Gifted}

Results of analyses on subjective outcome variables are reported in Table 2. All groups were satisfied with their lives, but parents were more satisfied than childless participants were, graduate student $F(1,519)=50.32, p<.001$; talent search $F(1,287.90)=$ 46.53, $p<.001$; indeed, the parents' scores were comparable to those of the happiest normative samples (Pavot \& Diener, 1993). Although there was no significant difference between men's and women's life satisfaction for graduate students, $F(1,519)=0.42$, $p=.518$, we did observe a significant gender difference for talent search participants, $F(1,287.90)=368.37, p<.001$. We also observed a significant interaction of gender and parenthood status among both groups: graduate student, $F(1,519)=5.64, p=.018$; talent search, $F(1,287.90)=14.55, p<.001$. Of the four groups, the mothers were most satisfied with their lives, and the childless women were least satisfied with theirs.

More than half of the participants of both samples were either satisfied or very satisfied with their careers. While differences were not large, a significantly higher proportion of graduate student parents were satisfied or very satisfied with their careers than were their childless same-gender counterparts, for men: $\chi^{2}(1, N=$ $272)=7.84, p<.01$; for women: $\chi^{2}(1, N=258)=5.47, p<.05$. 
Groups

$\hat{F}$ : Female participants with children by mid-30s F: Female participants without children by mid-30

Top Graduate Students in Their Mid-30s

Having a full-time career

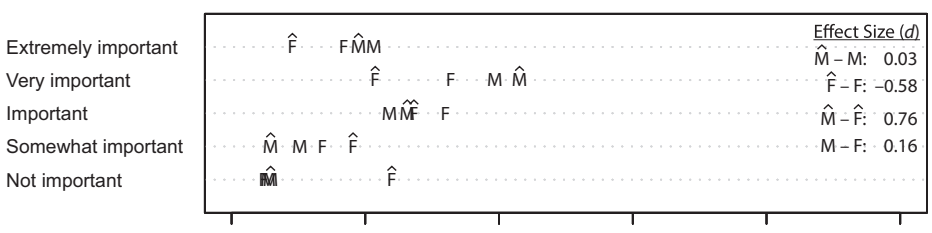

Having a part-time career

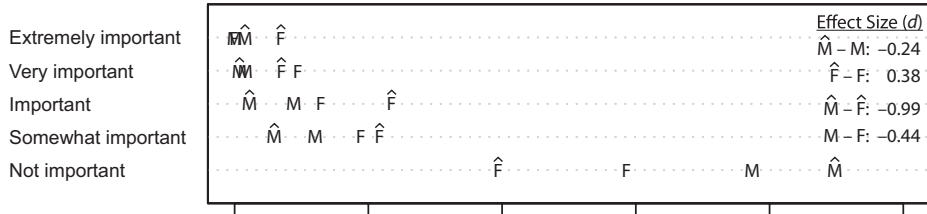

Having a part-time career for a limited time period

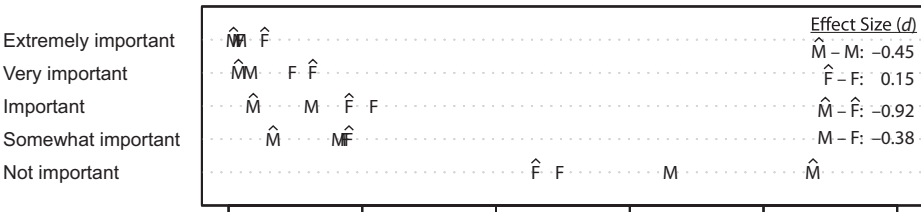

Not working outside the home

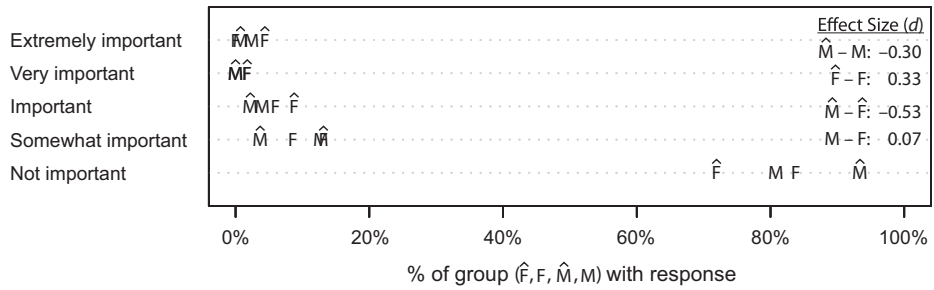

$\hat{\mathrm{M}}$ : Male participants with children by mid-30s M: Male participants without children by mid-30s

The Profoundly Gifted in Their Mid-30s

Having a full-time career

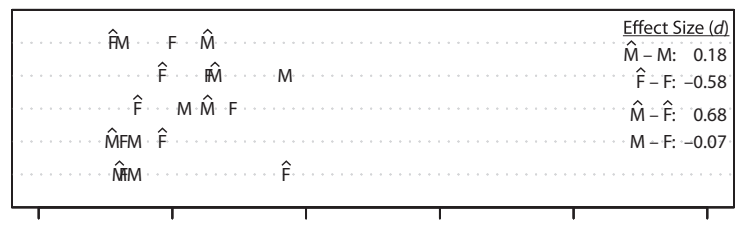

Having a part-time career

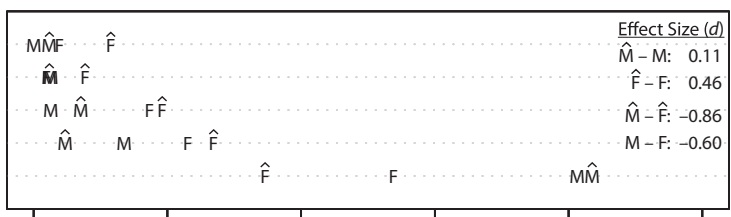

Having a part-time career for a limited time period

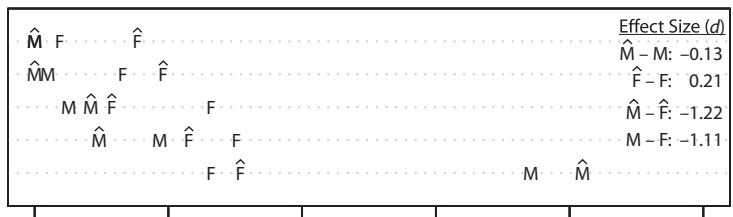

Not working outside the home

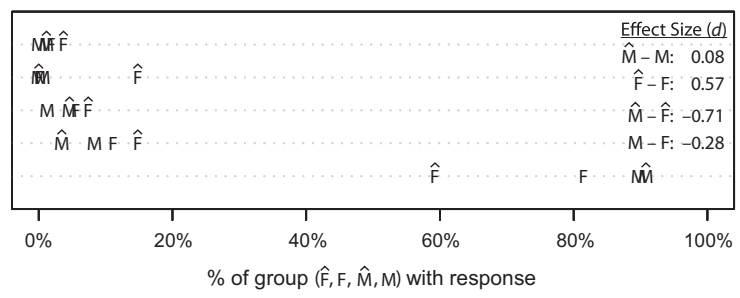

Figure 6. Frequency distributions of responses of math/science graduate students and the profoundly gifted in their mid-30s to items about life values. For graduate students, $p<.01$ for all $|d|>0.33$. For talent search participants, $p<.01$ for $\hat{M}-M|d|>0.35, \hat{F}-F|d|>0.65, \hat{M}-\hat{F}|d|>0.56, M-F|d|>0.45$.

Those effects were replicated among the talent search participants, although the magnitudes were not statistically significant for the women, for men: $\chi^{2}(1, N=263)=3.84, p<.05$; for women: $\chi^{2}(1, N=82)=0.079, p=.77$.

\section{Discussion}

In Study 2, we found not only similarities in lifestyle preferences between men and women in their mid-30s but also some differences that could contribute to gender differences in achievement, development, and orientation toward the world of work. These differences varied as a function of parenthood. In addition, we found that these men and women were satisfied with life and work despite any differences in preferences that may have existed among them.

As in Study 1, the graduate student men and women agreed on their personal views and life values in several areas, such as having children, having leisure time to enjoy interests outside of work, making a contribution to the greater good, and being a team player. Furthermore, the talent search participants replicated many of these similarities.

Second, some gender differences in values and views were replicated across cohorts: Men from both cohorts placed more value than the women did on having a full-time career, having lots of money, and being successful in their careers, and they agreed more than the women did that they wanted to be recognized as the best in their fields, that society should invest in their ideas because they are more important than those of other people in their discipline, and that they tended to put their own needs before others' needs. Women placed more value than men did on having a part-time career, having strong friendships, giving back to the community, and living close to family, and they agreed more than men did that it is important that no one goes without or gets left behind and that they can relatively easily multitask. The items that men endorsed more seem to reveal an elevated need for compen- 
sation, recognition, and influence in the workplace, and perhaps more of an intraindividual perspective, while the items the women endorsed more seem to indicate some reluctance to devote themselves fully to work and perhaps instead a preference to spread their commitments out among work, friends, family, and the community, or more of an interindividual perspective.

Third, these gender differences in values varied as a function of parenthood. Prototypic gender differences and gender differences for items regarding commitment to work were larger among parents than among nonparents: Success in work, inventing something that has an impact, having a full-time career or a part-time career, and working at home are all items that showed these differences. These genderdifferentiating patterns have been observed in the general population. Perhaps the best known characterization of these patterns in the psychological sciences is offered in Bakan's (1966) treatment The Duality of Human Existence, namely, agency and communion. More recent research has determined that agency (or competence) and communion (or warmth) are universal basic dimensions for judgments of self and others (Abele \& Wojciszke, 2007; Fiske, Cuddy, \& Glick, 2006). Furthermore, Abele (2003) has shown that agency in young adulthood predicts career success and that communion predicts involvement with family instead of career. This might mean that the more agentic men in our study will be more successful in their careers relative to the women in their cohort; but while communal traits are more closely tied with biological gender, agentic traits are malleable and corresponsive (Roberts, Caspi, \& Moffitt, 2003) with objective and subjective career success: That is, agency influences career success, and career success influences agency. Perhaps, if these gender differences indeed decrease after early parenthood, and women become more agentic, we will find that their career development and success peak later in life than the men's do.

Abele (2003) found also that German college graduates in STEM did not demonstrate differences in agency and communion and that the women had high agency scores relative to the rest of the participants in her study; however, the large majority of the participants in that study had no children. That gender differences in agency and communion do emerge among our participants is especially noteworthy because both cohorts are extremely able and high achieving. Moreover, the graduate student participants had similar ability, interest, and personality profiles in their early 20s, and they also had similar STEM educational experiences.

Our participants also had high levels of life and career satisfaction, and parents were more satisfied than childless participants were. $^{6}$ Additionally, we found an interaction between parenthood status and gender in their effect on life satisfaction among both cohorts. The mothers were most satisfied, followed by the fathers and the childless men; the childless women reported the least satisfaction with life overall. Perhaps the mothers-whose work preferences, life values, and personal views seem to stand out most from those of the other groups-were happy with their lives because their choices (e.g., motherhood) corresponded with their communal preferences. Ultimately, even though participants had some different and some similar ideas about what they valued in life, they were satisfied with life and were satisfied with their careers. They appeared content.

\section{General Discussion}

The goal of this research was to investigate empirically whether gender differences in lifestyle preferences and psychological orientation that may contribute to gender differences in occupational achievement develop among top math/science graduate students and the profoundly gifted during their emerging and young adulthood years. Overall, the patterns formed by these heterogeneous collections of work preferences, life values, and personal views indeed indicate somewhat different psychological orientations toward life for exceptionally talented and opportunity-advantaged men and women in their mid-30s, and these differences in orientations seem to be intensified by parenthood. Following the completion of their terminal graduate degrees, men seem to be more career-focused and agentic, whereas women appear to be more holistic and communal in their orientation toward life and more attendant to family, friends, and the social well-being of themselves and others more generally. Parenthood status seems to moderate some of the relationships, particularly those that involve commitment to work and its juxtaposition with commitment to family and the community. Furthermore, at least for graduate students, and likely other highly able men and women as well (Webb, Lubinski, \& Benbow, 2002), these orientations develop during emerging and young adulthood (Gottfredson, 1981, 2005; Hakim, 2000, 2006) and become increasingly important factors, along with stable personality traits and abilities, in people's career and life choices. Ultimately, despite their different priorities, both the men and women of these samples reported high levels of life satisfaction, which suggests that there are many paths to a satisfying life. ${ }^{7}$

The gender differences observed in this study seem to indicate that, while these highly capable men and women have many psychological similarities, they nevertheless take somewhat different approaches to managing their multiple roles in life during the decade following their formal education that are reminiscent of Bakan's (1966) formulation of agency and communion. That this

\footnotetext{
${ }^{6}$ Many of the Work Preferences, Life Values, and Personal Views items were assessed as part of the age 23 (10-year) and/or age 33 (20-year) follow-ups of two other SMPY cohorts of talent search participants $(N=$ 1,975), who were identified between 1972 and 1979 as being in the top $1 \%$ in quantitative reasoning ability (Benbow, Lubinski, Shea, \& EftekhariSanjani, 2000). For replication purposes we calculated effect sizes to determine if the gender differences found in these additional groups replicated those of the graduate student and profoundly gifted samples. These results are presented in the online Supplemental Material (see Tables S5 and S6). The older cohort, identified in the early 1970s, was administered the Work Preferences items and demonstrated many of the same similarities and differences between the genders in their age 33 responses to the Work Preferences items as the graduate students did; likewise, both cohorts replicated the similarities and differences found among the Life Values of the graduate student and profoundly gifted groups. Thus, the gender differences in lifestyle preferences observed in this study appear to be fairly robust and stable over time and over multiple high-ability cohorts.

${ }^{7}$ Of course, these participants could have been happier to begin with, before they became parents. Therefore we examined this possibility among these participants at the time of the mid-20s follow-up and found no systematic effects in a host of indicators indexing emotional well-being on measures of self-esteem and internal locus of control taken from their Time 1 survey (Lubinski, Benbow, et al., 2001; Lubinski, Webb, et al., 2001).
} 
is true of the graduate students is especially noteworthy, because they were similar in their abilities, educational-vocational preferences, and educational experiences at age 25 (Lubinski, Benbow, et al., 2001). In their mid-30s, the men focused on and valued status in their careers most; on the contrary, the women spread their attention among their roles more evenly, tending to give more weight than men did to their roles outside of work. For women, relative to men, family, friends, and social well-being outside of work tended to be more dominant life themes. These conclusions align with previous findings that women have more diffuse attention and men more focused attention (Johnson \& Bouchard, 2007a). Other research on gender differences in time willing to devote to current and ideal careers (Lubinski \& Benbow, 2006) also follows this pattern. These findings serve as a reminder that life is ipsative: Just as a decision in favor of working long hours might lead to greater success in one's career, it might also require sacrifices in one's personal life, and vice versa. However, sacrifices that some people consider merely inconvenient may be deemed wholly unacceptable by others (Lubinski \& Benbow, 2001).

Some especially intriguing patterns emerge when we examine the parents' and childless participants' responses separately. First, we observe larger gender differences among parents than among childless participants. Although they are at least as able as the remainder of the participants, the mothers stand out in their commitment to short, flexible work weeks and part-time work. Additionally, it is clear that both the men and the women studied here varied within gender in their preferences and views. Although the men with and without children responded similarly to most of the items we presented in Figures 3, 6, S1, and S2, we observed more variation in the women's responses: In some cases the responses of the childless women were more similar to those of the men than to those of the women with children. These results align with previous findings that many childless women, like most men, are work-centered, valuing competitive rivalry, achievement orientation, and individualism, in contrast to other women, who either prioritize family life and children-valuing caring, sharing, and community (home-centered women)—or reconcile these two sets of values, as seen with Hakim's $(2000,2006)$ adaptive women. Other findings suggest that childless women find less satisfaction in work than in relationships, however (Rhoads, 2004).

We have observed among these cohorts of highly talented participants a finding well known in the study of individual differences: The differences observed between the genders pale in comparison to the individual differences observed within the genders for both parents and nonparents, as can be observed in the means and standard deviations that we provide for all of our items. While it is appropriate to aggregate individual difference variables to understand over- and underrepresentation and differential group trajectories (Lubinski \& Humphreys, 1996), the maximization of human capital and predictions about individuals require individual, and not group, appraisals (Gottfredson, 2002; Lubinski, 1996, 2000). Indeed, group membership often offers little if any added value once traditional measures of human individuality are taken into account (Hakim, 2007; Lubinski \& Humphreys, 1997; Webb et al., 2002).

Additionally, it is important to keep in mind that when modeling work adjustment, performance, and satisfaction on the basis of individual differences in specific abilities, educational-vocational preferences, and learning and work opportunities (Dawis \& Lofquist, 1984; Gottfredson, 1981, 2005; Lofquist \& Dawis, 1991), the determinants that bring people to certain niches for learning and work do not always remain dominant life forces (Browne, 2002, 2004-2005; Pinker, 2008; Rhoads, 2004; Rothman, 2006). Over time, developmental changes and changing life demands, such as parenthood, can shift priorities (Hakim, 2000, 2006). As similar as the graduate student men and women were in their mid-20s, it is clear that, on average, their relative levels of commitment to work diverged over the course of the ensuing decade. Demands from life domains outside of education and work appear to condition not only how specific abilities and educational-vocational preferences relevant to performance and choice in education and work are actualized, but also how people perceive and evaluate their own learning and work opportunities.

On average, the men and women in this study demonstrated differing lifestyle preferences and orientations toward life; in addition, they also displayed minor differences in career choices (Lubinski et al., 2006): In the graduate student sample, approximately $75 \%$ of the men and $65 \%$ of the women were professors, engineers, and scientists, while $0 \%$ of the men and $9 \%$ of the women were homemakers. In the profoundly gifted sample, approximately $57 \%$ of the men and $44 \%$ of the women were professors, engineers, and scientists, and $1 \%$ of the men and $9 \%$ of the women were homemakers. Nevertheless, their high career satisfaction and high life satisfaction both imply that the men and women simply, on average, found somewhat different ways to achieve happiness or a satisfying life.

These results likely have implications for the differential male/ female representation in time-intensive and high-level careers. At the least, they should be taken into account in future treatments of gender disparities in high-level occupations, especially for careers characterized by rapid changes in conceptual knowledge and technical sophistication, unpredictable hours, and travel demands at a moment's notice. Our findings suggest that both a lifespandevelopment perspective and the assessment of balance among broad life domains facilitate understanding life choices at the individual and group levels. It is not appropriate to judge women's career progression with men's career progression as the standard (Pinker, 2008). Their approaches are not the same; rather they are complementary: During young adulthood, men are more oriented toward advancing society through personal achievement, whereas women are more oriented toward maintaining society and keeping it alive. Broad dispositional attributes relevant to learning and work (abilities and educational-vocational interests), while clearly important determinants of behavior and development in educational settings and the world of work (Armstrong \& Rounds, 2008; Dawis, 1992; Dawis \& Lofquist, 1984; Gottfredson, 1981, 2005; Holland, 1996; Rounds \& Tracey, 1990), tell only part of the story. Consideration of ongoing developmental changes and fluctuations in life priorities-which surface during emerging adulthood, young adulthood, parenthood, and subsequent to one's formal education-is required to tell a more comprehensive story.

\section{References}

Abele, A. E. (2003). The dynamics of masculine-agentic and femininecommunal traits: Findings from a prospective study. Journal of Personality and Social Psychology, 85, 768-776. 
Abele, A. E., \& Wojciszke, B. (2007). Agency and communion from the perspective of self versus others. Journal of Personality and Social Psychology, 93, 751-763.

Allport, G. W., Vernon, P. E., \& Lindzey, G. (1970). Manual: Study of values. Boston: Houghton Mifflin.

Armstrong, P. I., \& Rounds, J. (2008). Vocational psychology and individual differences. In S. Brown \& R. Lent (Eds.), Handbook of counseling psychology (4th ed.; pp. 375-391). New York: Wiley.

Arnett, J. J. (2000). Emerging adulthood: A theory of development from the late teens through the twenties. American Psychologist, 55, 469480

Bakan, D. (1966). The duality of human existence: An essay on psychology and religion. Chicago: Rand McNally.

Becker, E., \& Lindsay, C. M. (2004). Assortative mating or glass ceiling: Under-representation of female workers among top earners. In S. W. Polachek (Ed.), Research in labor economics (Vol. 23, pp. 235-267). New York: Elsevier.

Benbow, C. P., Lubinski, D., Shea, D. L., \& Eftekhari-Sanjani, H. (2000). Gender differences in mathematical reasoning ability at age 13: Their status 20 years later. Psychological Science, 11, 474-480.

Benbow, C. P., Lubinski, D., \& Suchy, B. (1996). The impact of SMPY's educational programs from the perspective of the participant. In C. P. Benbow \& D. Lubinski (Eds.), Intellectual talent: Psychometric and social issues (pp. 266-300). Baltimore: Johns Hopkins University Press.

Brody, N. (1992). Intelligence (2nd ed.). San Diego, CA: Academic Press.

Browne, K. R. (2002). Biology at work: Rethinking sexual equality. New Brunswick, NJ: Rutgers University Press.

Browne, K. R. (2004-2005). Women in science: Biological factors should not be ignored. Cardozo Women's Law Journal, 509-528.

Byrnes, J. P., Miller, D. C., \& Schafer, W. D. (1999). Gender differences in risk-taking: A meta-analysis. Psychological Bulletin, 125, 367-383.

Caspi, A., Roberts, B. W., \& Shiner, R. L. (2005). Personality development: Stability and change. Annual Review of Psychology, 56, 453-484.

Ceci, S. J., \& Williams, W. M. (Eds.). (2007). Why aren't more women in science? Top researchers debate the evidence. Washington, DC: American Psychological Association.

Dawis, R. V. (1992). The individual differences tradition in counseling psychology. Journal of Counseling Psychology, 39, 7-19.

Dawis, R. V. (2001). Toward a psychology of values. Counseling Psychologist, 29, 458-465.

Dawis, R. V., \& Lofquist, L. H. (1984). A psychological theory of work adjustment: An individual differences model and its applications. Minneapolis: University of Minnesota Press.

Dunnette, M. D. (Ed.). (1976). Handbook of industrial and organizational psychology. Chicago: Rand McNally.

Dunnette, M. D., \& Hough, L. M. (Eds.). (1991). Handbook of industrial and organizational psychology (Vol. 2). Palo Alto, CA: Consulting Psychologists Press.

Dunnette, M. D., \& Hough, L. M. (Eds.). (1992). Handbook of industrial and organizational psychology (Vol. 3). Palo Alto, CA: Consulting Psychologists Press.

Ericsson, K. A. (Ed.). (1996). The road to excellence: The acquisition of expert performance in the arts and sciences, sports and games. Mahwah, NJ: Erlbaum.

Eysenck, H. (1995). Genius: The natural history of creativity. Cambridge, United Kingdom: Cambridge University Press.

Fiske, S. T., Cuddy, A. J. C., \& Glick, P. (2006). Universal dimensions of social cognition: Warmth and competence. Trends in Cognitive Sciences, 11, 77-83.

Geary, D. C. (1998). Male, female: The evolution of human gender differences. Washington, DC: American Psychological Association.

Geary, D. C. (2000). Evolution and proximate expression of human paternal investment. Psychological Bulletin, 126, 55-77.

Geary, D. C. (2005). The origin of mind: Evolution of brain, cognition, and general intelligence. Washington, DC: American Psychological Association.

Gottfredson, L. S. (1981). Circumscription and compromise: A developmental theory of occupational aspirations. Journal of Counseling Psychology, 28, 545-579.

Gottfredson, L. S. (2002). Assess and assist individuals, not sexes. Issues in Education, 8, 39-47.

Gottfredson, L. S. (2005). Applying Gottfredson's theory of circumscription and compromise in career guidance and counseling. In S. D. Brown \& R. W. Lent (Eds.), Career development and counseling: Putting theory and research to work (pp. 71-100). Hoboken, NJ: Wiley.

Gough, H. G., \& Heilbrun, А. B. (1983). The Adjective Checklist manual. Palo Alto, CA: Consulting Psychologists Press.

Gourman, J. (1989). The Gourman report: A rating of graduate and professional programs in American and international universities. Los Angeles: National Educational Standards.

Greenberger, E., \& O’Neil, R. (1993). Spouse, parent, worker: Role commitments and role-related experiences in the construction of adults' well-being. Developmental Psychology, 29, 181-197.

Gutmann, D. (1987). Reclaimed powers: Toward a new psychology of men and women in later life. New York: Basic Books.

Hakim, C. (2000). Work-lifestyle choices in the 21st century: Preference theory. Oxford, United Kingdom: Oxford University Press.

Hakim, C. (2006). Women, careers, and work-life preferences. British Journal of Guidance and Counseling, 34, 279-294.

Hakim, C. (2007). Dancing with the devil? Essentialism and other feminist heresies. British Journal of Sociology, 58, 123-132.

Halpern, D. F., Benbow, C. P., Geary, D. C., Gur, R., Hyde, J. S., \& Gernsbacher, M. A. (2007). The science of gender differences in science and mathematics. Psychological Science in the Public Interest, 8, 1-51.

Harmon, L. W., Hansen, J. C., Borgen, F. H., \& Hammer, A. L. (1994). Applications and technical guide for the Strong Interest Inventory. Palo Alto, CA: Consulting Psychologists Press.

Hedges, L. V., \& Nowell, A. (1995, July 7). Gender differences in mental test scores, variability, and numbers of high-scoring individuals. Science, 269, 41-45.

Helson, R., Pals, J., \& Solomon, M. (1997). Is there adult development distinctive to women? In R. Hogan, J. Johnson, \& S. Briggs (Eds.), Handbook of personality psychology (pp. 291-314). San Diego, CA: Academic Press.

Holland, J. L. (1996). Exploring careers with a typology: What we have learned and some new directions. American Psychologist, 51, 397-406.

Jackson, D. N., \& Rushton, J. P. (1985). Scientific excellence: Origins and assessment. Newbury Park, CA: Sage.

Jensen, A. R. (1998). The g factor. Westport, CT: Praeger.

Johnson, W., \& Bouchard, T. J., Jr. (2007a). Gender differences in mental ability: $\mathrm{g}$ masks the dimensions on which they lie. Intelligence, 35 , 23-39.

Johnson, W., \& Bouchard, T. J., Jr. (2007b). Gender differences in mental ability: A proposed means to link them to brain structure and function. Intelligence, 35, 197-209.

Levinson, D. J. (1978). The seasons of a man's life. New York: Knopf.

Lippa, R. A. (1998). Gender-related individual differences and the structure of vocational interests: The importance of the people-things dimension. Journal of Personality and Social Psychology, 74, 996-1009.

Lippa, R. A. (2005). Gender, nature, and nurture. Mahwah, NJ: Erlbaum. Lippa, R. A. (2006). The gender reality hypothesis. American Psychologist, 61, 639-640.

Lix, L. M., \& Keselman, H. J. (1995). Approximate degrees of freedom tests: A unified perspective on testing for mean equality. Psychological Bulletin, 117, 547-560.

Lofquist, L. H., \& Dawis, R. V. (1991). Essentials of person-environmentcorrespondence counseling. Minneapolis: University of Minnesota Press. 
Lubinski, D. (1996). Applied individual differences research: Its quantitative methods and its policy relevance. Psychology, Public Policy, and Law, 2, 187-203.

Lubinski, D. (2000). Scientific and social significance of assessing individual differences: "Sinking shafts at a few critical points." Annual Review of Psychology, 51, 405-444.

Lubinski, D., \& Benbow, C. P. (2001). Choosing excellence. American Psychologist, 56, 76-77.

Lubinski, D., \& Benbow, C. P. (2006). Study of mathematically precocious youth after 35 years: Uncovering antecedents for the development of math-science expertise. Perspectives in Psychological Science, 1, 316345 .

Lubinski, D., Benbow, C. P., Shea, D. L., Eftekhari-Sanjani, H., \& Halvorson, M. B. J. (2001). Men and women at promise for scientific excellence: Similarity not dissimilarity. Psychological Science, 12, 309317

Lubinski, D., Benbow, C. P., Webb, R. M., \& Bleske-Rechek, A. (2006). Tracking exceptional human capital over two decades. Psychological Science, 17, 194-199.

Lubinski, D., \& Humphreys, L. G. (1996). Seeing the forest from the trees: When predicting the behavior or status of groups, correlate means. Psychology, Public Policy, and Law, 2, 363-376.

Lubinski, D., \& Humphreys, L. G. (1997). Incorporating general intelligence into epidemiology and the social sciences. Intelligence, 24, 159201.

Lubinski, D., Webb, R. M., Morelock, M. J., \& Benbow, C. P. (2001). Top 1 in 10,000: A 10-year follow-up of the profoundly gifted. Journal of Applied Psychology, 86, 718-729.

Lykken, D. T. (1968). Statistical significance in psychological research. Psychological Bulletin, 70, 151-159.

Lykken, D. T. (1991). What's wrong with psychology anyway? In D. Ciccetti \& W. Grove (Eds.), Thinking clearly about psychology (pp. 3-39). Minneapolis: University of Minnesota Press.

Maxwell, S. E., \& Delaney, H. D. (2004). Designing experiments and analyzing data: A model comparison perspective (2nd ed.). Mahwah, NJ: Erlbaum.

McDowell, J. M. (1982). Obsolescence of knowledge and career publication profiles: Some evidence of differences among fields in costs of interrupted careers. American Economic Review, 72, 752-768.

Murray, C. (2003). Human accomplishment: The pursuit of excellence in the arts and sciences, 800 B.C. to 1950. New York: HarperCollins.

National Research Council. (1987). Summary report 1986: Doctoral recipients from United States universities. Washington, DC: National Academies Press.

Park, G., Lubinski, D., \& Benbow, C. P. (2007). Contrasting intellectual patterns for creativity in the arts and sciences: Tracking intellectually precocious youth over 25 years. Psychological Science, 18, 948-952.

Park, G., Lubinski, D., \& Benbow, C. P. (2008). Ability differences among people who have commensurate degrees matter for scientific creativity. Psychological Science, 19, 957-961.

Pavot, W., \& Diener, E. (1993). Review of the Satisfaction With Life scale. Psychological Assessment, 5, 164-172.

Pinker, S. (2008). The sexual paradox: Men, women, and the real gender gap. New York: Scribner.

Rhoads, S. E. (2004). Taking gender differences seriously. San Francisco: Encounter Books.

Roberts, B. W., Caspi, A., \& Moffitt, T. E. (2003). Work experiences and personality development in young adulthood. Journal of Personality and Social Psychology, 84, 582-593.

Rothman, S. (2006, October 2). Bias doesn't stop female scientists. Daily Pennsylvanian. Retrieved April 17, 2009, from http:// media.www.dailypennsylvanian.com/media/storage/paper882/news/ 2006/10/02/Opinion/Sarah.Rothman.Bias.Doesnt.Stop.Female .Scientists-2318905.shtml

Rounds, J. B., \& Tracey, T. J. (1990). From trait-and-factor to personenvironment fit counseling: Theory and process. In W. B. Walsh \& S. H Osipow (Eds.), Career counseling (pp. 1-44). Hillsdale, NJ: Erlbaum.

Savickas, M. L. (2002). Career construction: A developmental theory of vocational behavior. In D. Brown \& Associates (Eds.), Career choice and development (4th ed., pp. 149-205). San Francisco: Jossey-Bass.

Savickas, M. L. (2005). The theory and practice of career construction. In S. D. Brown \& R. W. Lent (Eds.), Career development and counseling: Putting theory and research to work (pp. 71-100). Hoboken, NJ: Wiley.

Simonton, D. K. (1988). Scientific genius: A psychology of science. New York: Cambridge University Press.

Simonton, D. K. (1994). Greatness: Who makes history and why. New York: Guilford Press.

Simonton, D. K. (1999). Origins of genius: Darwinian perspectives on creativity. New York: Oxford University Press.

Strand, S., Deary, I. J., \& Smith, P. (2006). Gender differences in cognitive abilities test scores: A UK national picture. British Journal of Educational Psychology, 76, 463-480.

Tyler, L. E. (1974). Individual differences. Englewood Cliffs, NJ: Prentice-Hall.

Wai, J., Lubinski, D., \& Benbow, C. P. (in press). Spatial ability for STEM domains: Aligning over fifty years of cumulative psychological knowledge solidifies its importance. Journal of Educational Psychology.

Webb, R. M., Lubinski, D., \& Benbow, C. P. (2002). Mathematically facile adolescents with math-science aspirations: New perspectives on their educational and vocational development. Journal of Educational Psychology, 94, 785-794.

Zuckerman, H. (1977). Scientific elite. New York: Free Press.

Received April 21, 2008

Revision received March 6, 2009 Accepted March 16, 2009 